\author{
Hill and Upland Livestock Production \\ Occasional Publication No. 10-British Society of Animal Production 1985 \\ edited by T. J. Maxwell and R. G. Gunn
}

\title{
TWINNING IN BEEF CATTLE
}

\section{P. J. BROADBENT}

\section{North of Scotland College of Agriculture, 581 King Street, Aberdeen AB9 IUD}

$\mathbf{T}$ win calf production in beef cows is estimated to occur naturally at a rate of 0.01 to 0.04 . Raising the rate of reproduction in beef cows by induced twinning would increase output from the enterprise and help to maintain calf supply in the EEC as dairy cow numbers decline. Embryo transfer is the most practical and consistent method of inducing twinning in beef cows presently available. It has been estimated that using this method in mature cows would raise calf weaning rate by 0.31 and total weight of wcaned calves produced by 0.21 (Sreenan and Diskin, 1985) on a herd basis. Thus, the additional costs and problems associated with induced twinning have to be covered by the benefit of approximately $50 \mathrm{~kg}$ more weaned calf produced per cow calving.

The procedure of induced twinning by embryo transfer involves the contralateral transfer of a 7-day-old embryo, which may have been freeze-stored, to a previously inseminated, synchronised, recipient cow. Recipients must have a high natural conception rate and respond to synchronisation. The embryos are recovered non-surgically, or after slaughter, from super-ovulated donor cows. Response to the super-ovulation procedure is very variable with the number of embryos recovered per cow flushed ranging from 0 to 36 (P. J. Broadbent, unpublished). For induced twinning by embryo transfer to be commercially viable, it is necessary for an average of at least 6 good embryos per cow flushed to be recovered. This rcquires the development of more consistent super-ovulation procedures or a method for screening potential donor cows. With surgical or non-surgical contralateral transfer of an embryo to an inseminated recipient, it is possible to achieve a twinning rate of 0.4 to 0.5 . A further 0.1 cows will have single pregnancies resulting from the transferred embryo (Sreenan and Diskin, 1985) but this will not necessarily make a significant contribution to increased output.

Diskin and Sreenan (1985) showed that cows induced to be twin calving by embryo transfer had shorter gestation lengths and lower individual calf birth weights than their single calving counterparts in a spring-calving herd. However, P. J. Broadbent (unpublished) did not record a decrease in gestation length or a marked effect on calf birth weight in a limited number of twin-calving cows, calving in autumn. Therefore, gestation length and calf birth weight may be controlled by a combination of cow nutrition and climatic factors. The lower calf birth weights in twin-calving cows resulted in fewer assisted calvings and assistance was restricted to situations where there was simultaneous presentation of the calves or posterior presentation of one or both calves. No difference in the incidence of retained foetal membranes or re-breeding rate was found between single- and twin-calving cows but the viability of twin calves was lower due to their lighter birth weights (Diskin and Sreenan, 1985).

Twin-bearing cows require improved nutrition during pregnancy to avoid producing small, less viable calves. The energy model NOSCOW (Bruce, Broadbent and Topps, 1984), indicated that a $550 \mathrm{~kg}$ Hereford $\times$ British Friesian cow producing twin calves weighing $40 \mathrm{~kg}$ cach at birth would require an additional $1750 \mathrm{MJ}$ ME over the 32.6 GJ ME per year it requires when producing a single calf of $45 \mathrm{~kg}$ birth weight. Similarly, the total increase in energy requirement of a twin-suckling, twin-bearing cow is calculated to be 4 or $7 \mathrm{GJ} \mathrm{ME} \mathrm{per}$ year, depending on whether an increase in milk production of approximately $\mathbf{0 . 2 0}$ or $\mathbf{0 . 4 5}$, respectively, is required. There will also be an increased solid food requirement for twin calves. Higher levels of feed in pregnancy should improve calf birth weight and viability and it has been shown that the reduction in calf growth rate from birth to weaning of 0.16 observed by Diskin and Sreenan (1985) can be avoided in double-suckling calves by improved cow nutrition (School of Agriculture - Aberdeen, 1981).

Although a substantial proportion of the additional feed requirements can be provided relatively cheaply from grazed herbage, it will be necessary to supply up to half the increase using conserved forages or concentrates. If over-feeding of single-bearing cows and under-feeding of twin-bearing cows with consequent effects on calf size and viability, assisted calvings, food and labour costs is to be avoided, it will be necessary to develop techniques which enable the presence of twins to be detected at various stages of pregnancy both easily and cheaply.

\section{REFERENCES}

Bruce, J. M., Broadbent, P. J. and Topps, J. H. 1984. A model of the energy system of lactating and pregnant cows. Anim. Prod. 38: 351-362. 
Diskin, M. G. and Sreenan, J. M. 1985. Production and management aspects of single and twinbearing beef cows. Anim. Prod. (Abstr.). In Press.

SCHOOL OF AGriculture-AberdeEn. 1981. Research, Investigations and Field Trials, 1979-80.
SReenan, J. M. and Diskin, M. G. 1985. Manipulation of the reproductive rate to increase calf crop and output from the suckler herd. Anim. Prod. (Abstr.). In Press. 